\title{
AVALIAÇÃO DA QUALIDADE MICROBIOLÓGICA DE PRODUTOS COSMÉTICOS NOVOS E EM USO
}

\author{
EVALUATION OF THE MICROBIOLOGICAL QUALITY OF \\ NEW AND IN-USE COSMETIC PRODUCTS
}

\section{Ivyla Alanne de Sousaa, Dárcio Luiz de Sousa Júniorb, Cícero Roberto Nascimento

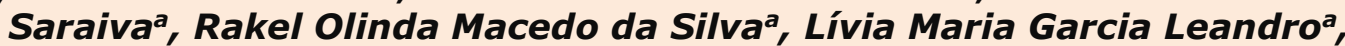 Maria Karollyna do Nascimento Silva Leandroa}

\author{
Centro Universitário Doutor Leão Sampaio \\ Universidade Regional do Caririb \\ E-mail: darciolsjr@gmail.com
}

\section{RESUMO}

Os cosméticos são utilizados pela população há muito tempo, servem para os mais diversos fins e, portanto, devem ser seguros e rentáveis. O presente estudo teve como objetivo a realização de pesquisa microbiológica para identificação de microrganismos em produtos cosméticos novos e em uso. Trinta produtos no total foram avaliados sendo quinze novos e quinze usados de diferentes marcas cosméticas. O preparo das amostras ocorreu utilizando o caldo de Infusão de Cérebro e Coração (BHI), para posterior pesquisa de microrganismos patogênicos utilizando meios específicos. Das quinze amostras novas de cosméticos três apresentaram contaminação por micro-organismos patogênicos como Staphylococcus aureus, Pseudomonas aeruginosa e Serratia marcescens e, das quinze amostras de produtos cosméticos usados, três estavam contaminados por Staphylococcus aureus. Consequentemente é importante que sejam estabelecidas normas de controle microbiológico com o propósito de se obter amostras de excelente qualidade, confiança e estabilidade.

Palavras-chave: Contaminação Microbiana; Cosméticos; Controle de qualidade.

\section{ABSTRACT}

Cosmetics have been used by the population for a long time, they serve the most diverse purposes and thus must be safe and cost-effective. The objective of the present study was to perform microbiological research to identify microorganisms in new and used cosmetic products. A total of thirty products were evaluated, fifteen new and fifteen used products of different cosmetic brands. The preparation of the samples occurred using Brain and Heart Infusion (BHI) broth, for subsequent research of pathogenic microorganisms using specific media. Of the fifteen new cosmetic samples, three showed contamination by pathogenic microorganisms such as Staphylococcus aureus, Pseudomonas aeruginosa, and Serratia marcescens, and of the fifteen used cosmetic product samples, three were contaminated with Staphylococcus aureus. Consequently, it is important that microbiological control standards are established with the purpose of obtaining samples of excellent quality, reliability and stability.

Keyword: Microbial Contamination; Quality Control; Cosmetics. 


\section{INTRODUÇÃO}

A Agência Nacional de Vigilância Sanitária (ANVISA), na resolução da diretoria Colegiada (RDC) $\mathrm{n}^{\circ} 211$ de 14 de julho de 2005 define os produtos cosméticos como preparações compostas por substâncias naturais ou sintéticas, de aplicação externa nas diversas partes do corpo humano, como a pele, sistema capilar, unhas, lábios, órgãos genitais externos, dentes e membranas mucosas da cavidade oral, com o propósito exclusivo ou principal de limpá-los, perfumá-los, alterar sua aparência, corrigir odores corporais, proteção ou mantê-los em bom estado (BRASIL, 2005).

Os produtos cosméticos são utilizados pelo homem desde épocas remotas, tendo em vista que durante a pré-história os homens já pintavam o próprio corpo. Relatos históricos descrevem que os egípcios foram os primeiros usuários de cosméticos e um exemplo disso foi a utilização do verde de malaquita que era utilizado como sombra de olhos e rouge, além de um corante extraído de uma planta de origem árabe utilizada para pintar os cabelos, a henna, a rainha Cleópatra se banhava com frequência com leite de cabra para manter a pele e cabelos hidratados (LEONARDI; RICCI, 2004).

De acordo com a Associação Brasileira das Indústrias de Higiene Pessoal, Perfumaria e Cosméticos (ABIHPEC), o mercado brasileiro de cosméticos está entre os mais elevados do mundo, ocupando o quarto lugar no ranking mundial, ficando atrás de EUA, China e Japão (ABIHPEC, 2016). Todas as formulações estão sujeitas a contaminação microbiana principalmente as de base aquosa, não somente no momento da fabricação, mas também durante o consumo, dessa forma, é imprescindível que essas formulações estejam devidamente conservadas (GOMES et al., 2015).

Com o intuito de minimizar riscos microbiológicos em produtos cosméticos, a etapa mais importante é a escolha dos conservantes (SIQUEIRA, 2005). A adição de conservantes na formulação cosmética visa aumentar o tempo de vida útil do produto, impedindo dessa forma a proliferação de microorganismos, os quais podem promover alterações do produto final e até mesmo causar doenças ao consumidor, portanto é necessária uma análise aprofundada desse padrão de qualidade, já que a manipulação desse tipo de material pode acarretar na transmissão indireta de fungos e bactérias (RABELLO, 2005; FELLINI; GALVÃO; GARVIL, 2015).

A qualidade microbiana é uma característica essencial para o funcionamento do produto, principalmente quanto à segurança e aceitabilidade, já que a presença de micro-organismos, a partir de determinada quantidade, promove a deterioração do mesmo, além de ocasionar riscos graves ao usuário. A fabricação de um produto cosmético envolve desde seu projeto a sua elaboração, sendo de suma importância a garantia da qualidade do produto final para assegurar a eficácia, inocuidade e aceitabilidade pelo consumidor (OHARA; SAITO, 1995; FELLINI; GALVÃO; GARVIL, 2015).

A qualidade microbiológica de produtos cosméticos representa um dos atributos essenciais para o seu desempenho satisfatório, principalmente quanto a sua segurança, qualidade, eficácia e aceitabilidade (BRASIL, 2008). Diante disso, o objetivo desse trabalho é analisar a qualidade microbiológica de produtos cosméticos novos e em uso e testar a inocuidade dos mesmos.

\section{METODOLOGIA}

\section{Obtenção das amostras}

Para realização da pesquisa foram coletadas amostras de produtos novos e em uso de diferentes marcas cosméticas. Os produtos usados foram selecionados de forma aleatória a partir da disponibilidade destes produtos pela população. Os cosméticos novos foram comprados de acordo com as amostras em uso obtidas para posterior comparação. No total foram analisadas 30 amostras. As análises ocorreram no laboratório de microbiologia do Centro Universitário Doutor Leão Sampaio - UNILEÃO. As metodologias empregadas para os ensaios microbiológicos foram baseadas no guia Detecção e Identificação de Bactérias de Importância Médica Módulo V da Agência Nacional de Vigilância Sanitária (ANVISA, 2005).

\section{Coleta e processamento das amostras}

30 produtos cosméticos ( 15 novos e 15 usados) foram coletados, os quais todos estavam dentro do prazo de validade, sendo esses de marcas diferentes, os produtos selecionados para análise foram: Gel capilar, shampoo, condicionador, hidratante corporal, desodorante corporal, máscara capilar, tônico capilar, sabonete líquido, batom, creme dental, sombra de olhos, 
esmalte de unha, sabonete em barra, pó facial e base facial, tanto novos quanto os em uso.

As amostras obtidas foram levadas em seu recipiente original para o laboratório de microbiologia do Centro Universitário Doutor Leão Sampaio - UNILEÃO, onde ficaram até o final das análises. Todos os materiais utilizados para o processamento das amostras foram previamente esterilizados. O preparos dos produtos ocorreu utilizando o Brain Heart Infusion (BHI), onde assepticamente a tampa do tubo foi removida e, com o auxílio de um swab, foi transferido uma pequena quantidade das amostras e incubadas em estufa bacteriológica a $37^{\circ} \mathrm{C}$ por 24 horas.

\section{Pesquisa de Staphylococcus aureus}

A partir do caldo de pré-enriquecimento não seletivo, com o auxílio de uma alça bacteriológica estéril foi realizado, em Ágar Manitol Salgado, um estriamento por esgotamento. As placas foram incubadas de maneira invertida em estufa bacteriológica por um período de 48 horas a $37{ }^{\circ} \mathrm{C}$ (BRASIL, 2004). Para a confirmação do crescimento sugestivo neste Ágar, foi avaliada a morfologia através da microscopia óptica utilizando a coloração de Gram e provas de coagulase utilizando o teste de aglutinação com plasma.

\section{Pesquisa de Pseudomonas aeruginosa}

A partir de colônias isoladas em cultura pura com 24 horas de crescimento, nos meios de inoculação primária, foi realizado o teste da oxidase e semeio em Ágar Mueller-Hinton, o qual foi incubado, de forma invertida, por um período de 48 horas a $30-35^{\circ} \mathrm{C}$.

\section{Pesquisa de Enterobactérias}

A partir do caldo de pré-enriquecimento não seletivo, uma alçada foi retirada e semeada, por esgotamento no Ágar MacConkey e em Ágar Eosin Methilene Blue (EMB) para pesquisa de Escherichia coli, todos incubados, de forma invertida, por um período de 48 horas a $30-35^{\circ} \mathrm{C}$. A identificação de Enterobactérias foi realizada através de testes bioquímicos onde a preparação dos tubos se deu da forma tradicional, utilizando tubos de ensaio esterilizados nos quais foram adicionados $2,5 \mathrm{ml}$ de meio.

\section{Testes Bioquímicos}

Urease
Esta prova foi realizada utilizando o meio com ureia, onde em cada tubo foi acrescentado $2,5 \mathrm{~mL}$ de meio. A prova consistiu em transferir uma porção do crescimento bacteriano com uma alça em agulha para o meio que foi incubado em estufa bacteriológica por 24 horas a $30-35^{\circ} \mathrm{C}$.

\section{Indol e gás sulfídrico}

Esta prova foi realizada utilizando $2,5 \mathrm{~mL}$ o meio SIM (Sulfato/Indol/Motilidade) que contém excesso de triptofano, tiossulfato como fonte de enxofre e o sulfato ferroso como indicador da produção de sulfeto de hidrogênio. A prova consistiu em transferir uma porção do crescimento bacteriano com uma alça em agulha para o meio, que foi incubado em estufa bacteriológica por 24 horas a $30-35{ }^{\circ} \mathrm{C}$. Após esse período de incubação para observar se houve produção de indol foi necessário adicionar ao meio $0,5 \mathrm{~mL}$ do reagente de Kovacs.

\section{Citrato}

A prova foi realizada no meio solido inclinado de Citrato de Simmons onde em cada tubo foi acrescentado $2,5 \mathrm{~mL}$ do meio que contém azul de bromotimol como indicador, o qual em $\mathrm{pH}$ 6,8 a 7,0 apresenta-se na cor verde. Foi realizado um semeio com a porção do crescimento bacteriano e em seguida o meio foi incubado em estufa bacteriológica por 24 horas a 30$35{ }^{\circ} \mathrm{C}$.

\section{Fermentação de carboidratos}

Essa prova foi realizada utilizando o meio Ágar Triple Sugar Iron (TSI) que tem na sua composição glicose, lactose e sacarose, em cada tubo foi acrescentado 2,5 mL desse meio. Foi realizado um semeio no meio sólido inclinado com a porção do crescimento bacteriano, em seguida o meio foi incubado em estufa bacteriológica por 24 horas a $30-35^{\circ} \mathrm{C}$.

\section{Fenilalanina}

A prova foi realizada utilizando 2,5 do meio fenilalanina, no qual com uma alça em agulha foi inoculado uma porção do crescimento bacteriano e em seguida o meio foi incubado em estufa bacteriológica por 24 horas a $30-35{ }^{\circ} \mathrm{C}$. Para observar o resultado foi adicionado ao meio 5 gotas de cloreto férrico $10 \%$. 


\section{RESULTADOS E DISCUSSÃO}

De acordo com a RDC n ${ }^{\circ} 481$, de 23 de setembro de 1999 (ANVISA) a avaliação de produtos cosméticos, perfumes e produtos para higiene pessoal devem atestar a ausência de micro-organismos patogênicos que possa ocasionar risco ao consumidor, além de determinar a carga microbiana viável presente no produto. Da investigação realizada com as 15 amostras novas, três apresentaram presença de micro-organismos patogênicos. Houve crescimento de $6,7 \%$ de Staphylococcus aureus no esmalte de unha, 6,7\% de Serratia marcescens no sabonete em barra e $6,7 \%$ de Pseudomonas aeruginosa na base facial (Gráfico 1). Segundo a legislação para produtos do tipo I Staphylococcus aureus e Pseudomonas aeroginosa devem estar ausentes (BRASIL, 1999).

Gráfico 1. Percentual do perfil de contaminação das amostras de cosméticos novas

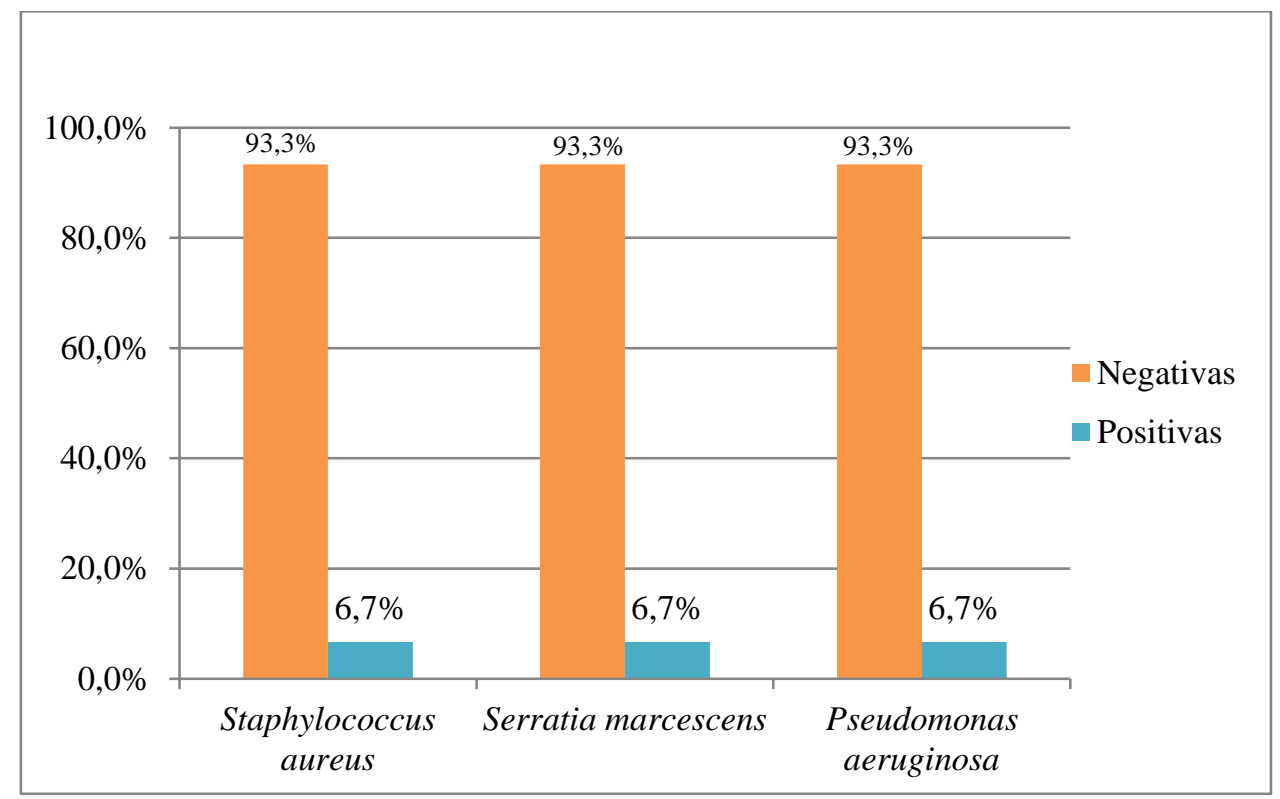

As análises microbiológicas das amostras de produtos cosméticos em uso podem ser observadas no gráfico 2. Em relação à pesquisa de micro-organismos, os resultados demostraram que $26,7 \%$ das amostras de gel capilar, tônico capilar, batom e base facial apresentaram contaminação por Staphylococcus aureus.

Gráfico 2. Percentual do perfil de contaminação das amostras de cosméticos.

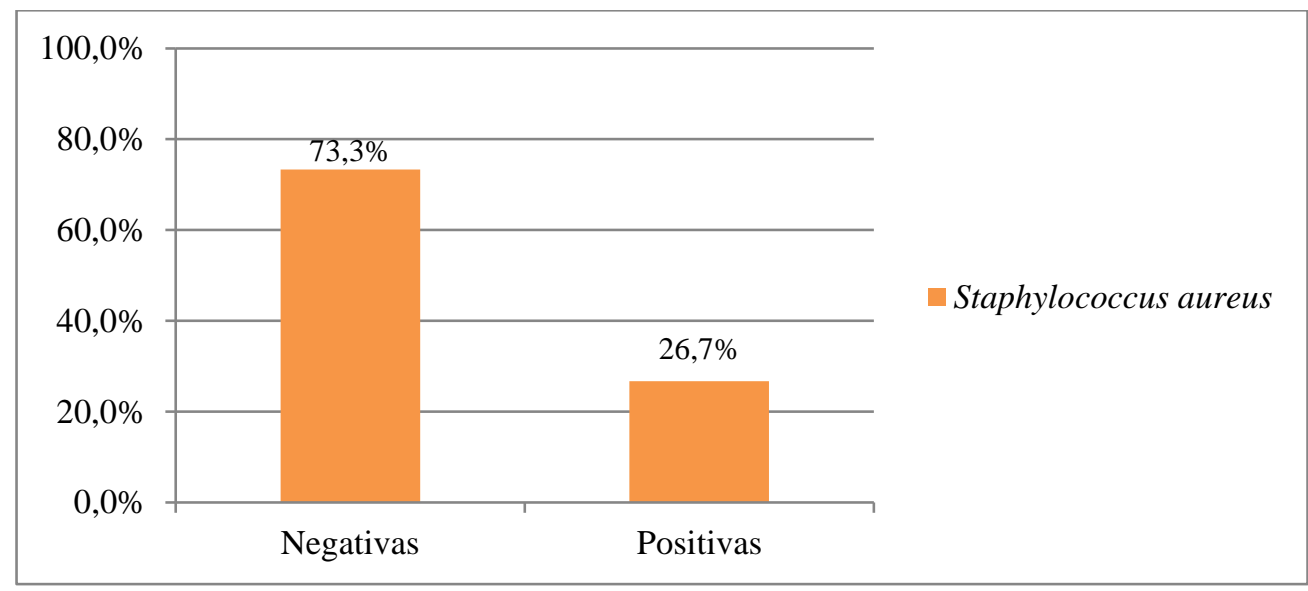


Dessa forma, com os resultados obtidos, analisando as amostras de acordo com a RDC $\mathrm{n}^{\circ}$ 481/1999, da ANVISA, duas amostras novas e quatro amostras usadas foram reprovadas, em consequência da presença dos patógenos $S$. aureus e $P$. aeruginosa. À vista disso os resultados apontam que tais produtos, tanto os novos quanto os usados, o sistema conservante não cumpriu sua finalidade de proteger o produto da contaminação microbiana. Além disso, uma amostra de produto cosmético nova apresentou Serratia marcescens, que embora não esteja descrita na resolução $\mathrm{n}^{\circ}$ 481/1999, é um micro-organismo oportunista responsável por várias infecções hospitalares (MENEZES et al., 2004).

Neste mesmo sentido, Rodrigues et al. (2020) analisaram batons de uso compartilhado quanto a presença de algumas bactérias potencialmente patogênicas e assim como este estudo, houve positividade para espécies como $S$. aureus, $P$. aeruginosa e Enterobactérias. O compartilhamento de cosméticos, principalmente maquiagens, é normalmente comum para a população, apesar de ser um foco de transmissão de micro-organismos que podem causar sérios problemas de saúde, diante disso, é imprescindível ressaltar, até como uma forma de prevenção, que o uso desses objetos deve ser individual.

De acordo com o estudo de Benvenutti et al. (2016), os quais investigaram 15 amostras de produtos cosméticos, foi mostrado que todas encontravam-se dentro dos limites especificados para contagem de micro-organismos aeróbios totais ( $<5 \times 102 \mathrm{UFC} / \mathrm{g})$. No entanto, foi evidenciado que, três amostras, uma de pó facial, uma de máscara para cílios e uma sombra, apresentaram contaminação por Staphylococcus coagulase positiva, sugestivo para Staphylococcus aureus, bactéria capaz de causar muitos danos com a sua infecção, sendo um resultado semelhante do presente estudo.

Em um estudo realizado por Yamamoto et al. (2004), no qual foram analisadas 240 amostras nas formas de matérias-primas, entre elas: cremes e loções, sabonetes, xampús, condicionadores capilares, géis, extratos de plantas, cápsulas, xaropes, líquidas, emulsões, suspensões e outras, foram encontradas contaminação, onde 2 amostras foram reprovadas pela presença de Escherichia coli e 1 amostra reprovada pela presença de Pseudomonas aeruginosa e Staphylococcus aureus.

Segundo um estudo realizado por Razooki, Saeed e Hamza (2009) com 60 produtos cosméticos usados foi encontrada contaminação onde o nível mais elevado de contaminação ocorreu em xampus onde foram identificados Pseudomonas sp., Shigella sp. e coliformes fecais. Pseudomonas sp. é considerada um microrganismo oportunista, pois causa doenças em indivíduos imunocomprometidos (MURRAY et al., 2000). Já a infecção ocasionada por Escherichia coli depende da sua composição antigênica (CAMPOS; FRANZOLIN; TRABULSI, 2004).

Lacerda, Benz e Neto (2017) realizou um estudo no qual foram analisadas seis amostras de protetores solares novos coletados de diferentes farmácias magistrais. Os resultados evidenciaram que as seis amostras de filtro solar apresentaram resultado positivo para contaminação por Staphylococcus aureus, segundo Pinto, Kaneko e Ohara (2003) a presença do Staphylococcus aureus pode estar associado a hábitos incorretos de higiene dos manipuladores do produto.

Rocha (2016) realizou uma análise da qualidade microbiológica de cremes hidratantes capilares em uso, no qual foram avaliadas seis amostras, na qual uma amostra sugeriu a presença de Pseudomonas aeruginosa que é uma bactéria patogênica para o ser humano. A importância clínica da infecção por $P$. aeruginosa é caracterizada através da expressão de múltipla resistência a antibacterianos, associada a uma difícil erradicação da doença com elevados índices de morbidade e mortalidade (LIVEMORE, 2002).

Considerando os estudos citados acima, o presente trabalho obteve resultados semelhantes em relação à presença de Pseudomonas aeruginosa e Sthapylococcus aureus, além disso, neste trabalho houve também a presença da bactéria Serratia marcescens, entretanto na avaliação deste estudo não houve contaminação por Escherichia coli, Micrococcus, Corynebacterium, Acinetobacter, Bacillus, e Moraxella mostrando discordância com a literatura apresentada. De acordo com Sutton e Singer (2006) a preocupação maior relacionada a produtos cosméticos é em relação ao controle de qualidade do produto, já que as presenças de agentes patogênicos acarretam danos à saúde do consumidor podendo ocasionar infecções ao usuário em decorrência do produto.

\section{CONCLUSÃO}

Através dos resultados obtidos verificou-se que duas amostras novas e três usadas apresentaram-se fora dos parâmetros estabelecidos pela RDC no 481/1999, da ANVISA, devido à confirmação da presença de Staphylococcus aureus e Pseudomonas aeruginosa.

Dessa forma este estudo reforça a importância 
do controle de qualidade microbiológico e ressalta a importância de estabelecer normas de controle para que seja obtido um produto de excelente qualidade, confiança e estabilidade, além disso, é importante que haja comunicação com o consumidor para evitar possível contaminação do produto pelo mau uso. Essas medidas são indispensáveis como forma de evitar tanto reações adversas relativamente simples já que produtos tópico podem ocasionar sérios riscos ao consumidor.

\section{REFERENCES}

ABIHPEC. Associação brasileira da indústria de higiene pessoal, perfumaria e cosméticos. 2016. Disponível em: http://www.abihpec.org.br. Acesso em: 20 de set. 2017.

BENVENUTTI, A. S.; VEIGA, A.; ROSSA, L. S.; MURAKAMI, F. Avaliação da qualidade microbiológica de maquiagens de uso coletivo. Arquivos de Ciências da Saúde da UNIPAR, v. 20, n. 3, 2016. DOI: https://doi.org/10.25110/arqsaude.v20i3.2016.5701.

BRANDÃO, R. et al. Análise microbiológica de bases cosméticas faciais. Revista Eletrônica Faculdade Montes Belos, v. 8, n. 1, 2015. Disponível em: http://www.revista.fmb.edu.br/index.php/fmb/article/vie $\mathrm{w} / 15 / 12$.

BRASIL. Guia de controle de qualidade de produtos cosméticos: uma abordagem sobre os ensaios físicos e químicos. Agência Nacional de Vigilância Sanitária, 2008 .

BRASIL. Resolução de Diretoria Colegiada no 332/05 Ministério da Saúde. Agência Nacional de Vigilância Sanitária, 2005.

BRASIL. Resolução de diretoria colegiada $n^{\circ}$ 481/99 Ministerio da Saúde. Agencia Nacional de vigilância Sanitária, 1999.

CAMPOS, L. C.; FRANZOLIN, M. R.; TRABULSI, L. R. Diarrheagenic Escherichia coli categories among the traditional enteropathogenic E. coli O serogroups: a review. Memorias do Instituto Oswaldo Cruz, v. 99, n. 6, p. 545-552, 2004. DOI: https://doi.org/10.1590/S007402762004000600001 .

FELLINI, B. P.; GALVAO, R. D.; GARVIL, M. P. AVALIAÇÃO MICROBIANA DE BASES COSMÉTICAS DO TIPO LANETTE. e-RAC, v. 4, n. 1,
2015.

Disponível

em:

http://adsunix.unitri.edu.br/erac/index.php/e-

rac/article/view/528/318.L.

LACERDA, A.; BENZ, C. F.; NETO, O. C. Análise fotoquímica e microbiológica de protetores solares produzidos nas farmácias de Colatina-ES. Unesc em Revista, v. 1, n. 2, p. 27-43, 2017. Disponível em: http://200.166.138.167/ojs/index.php/revistaunesc/articl e/view/23.

LEONARDI, RICCI, G. Cosmetologia Aplicada. 1. ed. São Paulo: Medfarma, 2004.

LIVERMORE, David M. Multiple mechanisms of antimicrobial resistance in Pseudomonas aeruginosa: our worst nightmare?. Clinical infectious diseases, v. 34, n. $5, \quad$ p. 634-640, 2002. DOI: https://doi.org/10.1086/338782.

MENEZES, E. A.; CEZAFAR, F. C.; ANDRADE, M. S. S.; ROCHA, M. V. A. P.; CUNHA, F. A. Freqüência de Serratia sp em Infecções Urinárias de pacientes internados na Santa Casa de Misericórdia em Fortaleza. Revista da Sociedade Brasileira de Medicina Tropical, v. 37 , n. 1, p. 70-71, 2004. DOI: https://doi.org/10.1590/S0037-86822004000100020.

MURRAY, P. R. et al. Microbiologia médica. Ed. Rio de Janeiro: Guanabara Koogan, 2000.

OHARA, M. T.; SAITO, T. Application of triphenyltetrazolium chloride in microbial limit test of pharmaceuticals and cosmetics. Journal of AOAC International, v. 78 , n. 6, p. 1525-1529, 1995. DOI: https://doi.org/10.1093/jaoac/78.6.1525.

PINTO, T. J. A.; KANEKO, T. M.; OHARA, M. T. Controle biológico de qualidade de produtos 
farmacêuticos, correlatos e cosméticos. 2.ed. São Paulo: Atheneu, 2003.

RABELLO, T. Guias de produtos cosméticos. Cosmetics\&toiletries. $6^{\mathrm{a}}$ ed. 2005.

RAZOOKI, R.; SAEED, E.; HAMZA, H. A study on Cosmetics Products Marketed in Iraq: Microbiological Aspects. Iraqi J. Pharm Sci, v. 18, n. 2, p. 20-25, 2009.

ROCHA, Nicolle Silva. Análise de qualidade microbiológica e físico-química de cremes hidratantes capilares comerciais em uso. Trabalho de Conclusão de Curso (Universidade de Brasília). 2016. Disponível em: https://bdm.unb.br/handle/10483/15624.

RODRIGUES, L. R; MENEZES, J. V. F.; SOUSA JÚNIOR, D. L.; MENDES, R. C. Análise Microbiológica de Batons de Uso Compartilhado na Cidade de Juazeiro do Norte-CE. Ensaios e Ciência C Biológicas Agrárias e da Saúde, v. 24, n. especial, 2020.
SIQUEIRA, V. L. Cuidados microbiológicos em cosméticos e produtos de higiene pessoal. Informativo CRQ-IV, 2005. Disponível em: https://www.crq4.org.br/informativomat_394.

SUTTON, S.; SINGER, D. Microbiological Best Laboratory Practices, USP $<1117>$ Value and Recent Changes to a Guidance of Quality Laboratory Practices. Amer Pharm Rev May/June, p. 41-47, 2011. Disponível em:

http://citeseerx.ist.psu.edu/viewdoc/download?doi=10.1 .1.699.3998\&rep=rep1\&type=pdf.

YAMAMOTO, C. H.; PINTO, T. J. A.; MEURER, V. M.; CARVALHO, A. M.; REZENDE, P. Controle de qualidade microbiológico de produtos farmacêuticos, cosméticos e fitoterápicos produzidos na Zona da Mata, MG. In: Congresso Brasileiro de Extensão Universitária. 2004. p. $1-7$ 